\title{
Power Quality Improvements in Wind Diesel Power Generation System
}

\author{
Omar Feddaoui ${ }^{1}$, Riad Toufouti ${ }^{1}$, Salima Meziane ${ }^{1}$ \\ Department of Electrical Engineering University of Mohammed ChérifMessaadia Souk Ahras, Algeria \\ omarispower@hotmail.com, toufoutidz@yahoo.frmeziane_elc@yahoo.fr
}

\begin{abstract}
Generation of electricity using diesel is costly for small remote isolated communities. At remote location electricity generation from renewable energy such as wind can help reduce the overall operating costs by reducing the fuel costs. However, the penetration of wind power into small diesel-based grids is limited because of its effect on power quality and reliability. This paper focuses on the combination of Wind Turbine and Diesel Generator systems for sustained power generation to improve the power quality of wind generation system. The performance of the optimal control structure are assessed and discussed by means of a set of simulations.
\end{abstract}

Keywords- Triple - renewable energy, wind diesel system, a synchronous generator, asynchronous generator, diesel generators, micro grid;

\section{INTRODUCTION}

Global warming is one of the most serious environmental problems facing the world community today. Scientistsare highly interested in solving it. It is characterized by the increase in the average temperature of the earth and extreme weather conditions ${ }^{1}$. On top of that, the rapid depletion of fossil fuels worldwide has necessitated an urgent search for another alternative energy sources to meet the current human requirements. Wind power is one of the renewable energy sources that scientists have recently drawn attention to ${ }^{2}$. Being an abundantly availableand non-pollutingenergy, it can make a wonderful alternative source of power. Moreover, this clean alternative source of energycan fit attractively for many usesand applications. On the hand, only $6.4 \%$ of total renewable energy sources available in the world are in use today. To get more consistent flow of energy to the user request, there has been a growing trend to combine renewable energy sources with diesel generators, giving a hybrid power generation system ${ }^{4}$.They are activated to serve as an electrical energy source in telecommunication systems or clinics in border crossings, remote areas, desertsand isolated habitats. These locationsneed systems which are generally independent from large interconnected networks ${ }^{5}$. In literature thousands of researches have been doneto find a way that hybrid systems could becontinually utilized in an isolated area or be connected to a power grid. $\ln ^{6}$ a study a hybrid autonomous system was introduced and presented $\mathrm{as}^{7}$ a power system in an island in Bangladesh. Several parameters are entered in the study as well as in the system design, but in books it is difficult to find how to measure the various components of an autonomous system.Most of the books focus on the basic technologicaltheory of the device, not the measurements of equipment. Variable parameters of most of renewable energy sources often take a complex control system ${ }^{8}$. However,the design of the right voltage and frequency used tocontrol a wind-diesel system is shown $\mathrm{in}^{9}$. $\operatorname{In}^{10} P$. S. Panickar et al study a strategy of adaptive control by a variable wind speed for an application for a wind-diesel hybrid system. Modeling is also a major factor in studies developed to simulate a functioning system. Much software allows us to do that. There is an example of modeling and simulating various hybrid systems presented with MATLAB-Simulink software in ${ }^{11}, 12$. In ${ }^{13}$ a model of a hybrid power generation is made by the HOMER software.To improve the quality of the energy produced by a system of wind energy production, a wind-diesel hybrid system is proposed in this study. Simulation results in Matlab \Simulink are presented to confirm the proper functioning of the wind diesel hybrid system to reduce greenhouse gas emissions.

\section{DIFFERENT STRUCTURES OF HYBRID SYSTEM}

The configuration of the hybrid system obviously depends on the availability and use constraints of energy resources. This requires a measurement and a preliminary analysis of site conditions.

There are several structures of an autonomous wind-diesel hybrid system: wind-diesel system with short-term storage, wind-diesel system with longterm storage (Batteries, compressed air, hydrogen, etc. $)^{14}$ and wind-diesel system without energy storage. The choice of a suitable structure of a hybrid system is connected to two parameters. The first is the satisfaction of the technical performance in meeting the requirements of power quality; whereas the second is theeconomicincrease of saving fuel. Thus, the costs of electricity production in the autonomous systemswill beminimized $^{15}$.

\section{WIND-DIESEL WITHOUT STORAGE}

In our study we chose to work on the third structure of wind-diesel system without energy storage (Figure 1). 


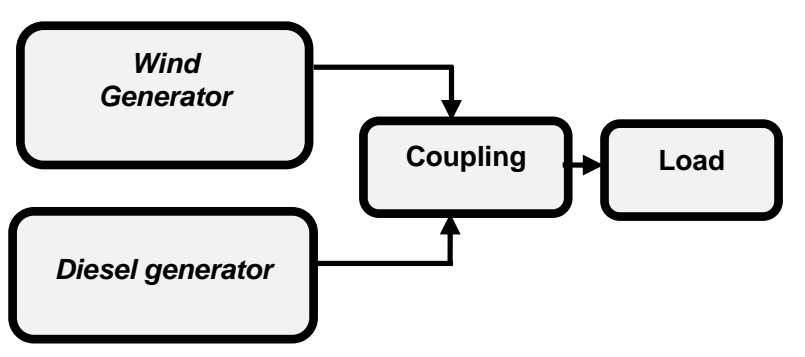

Fig.1. Simplified diagram of a wind diesel hybrid system

It is able to meet the need for electricity for consumers in isolated zones.It consists of the following subsystems: a wind generator and some diesel both connected to a load.

During the functionality of the system studied, if the electricity generated by the wind generator is sufficient for the load demand, the diesel generator is inactive to producereactive energy compensation. Except in the case where wind energy is insufficient to load demand, the diesel generator goes on to provide additional energy.

\section{A. Wind generator}

A wind turbine consists of four main components: a turbine which is the main tool for the conversion of wind energy into mechanical energy,an electromechanical system as a tool for transformation of mechanical energy into electrical energy.It includes the asynchronous generator and associated electrical components. An interconnect system and a control system [13].

The low cost and the standardization of the asynchronous machine that does not require a complex installation has led to a wide domination of this type of generators installed in a wind system. It is less demanding in terms of maintenance and has a failure rate which is very low. In the wind turbine consequent size, rotation speed is low. It is therefore necessary to inserta mechanical speed multiplier between the turbine and the induction motor. In this work we will focus to study on an asynchronous machine squirrel cage self-excited. (Figure 2)

PSM requires reactive energy to start (generation of rotating magnetic field). In a general case a capacitor connected in parallel with the stator circuit provide this energy [16].

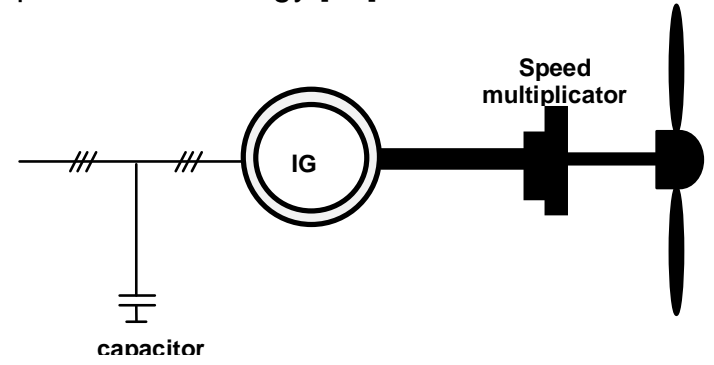

Fig.2. Wind System

\section{B. Diesel generator}

The diesel generator (Figure 3) is generally composed of a synchronous generator coupled to a diesel engine. The frequency of the alternating output current is maintained by a speed regulator. The regulator operates by adjusting the flow of fuel to keep the engine speed and the speed of the generator constant.In the case of high speed wind, the clutch decouples the synchronous generator from the diesel engine, and the machine functions as a synchronous generator and provides reactive energy [16, 23].

Diesel engines are more efficient than internal combustion engines. The speed of rotation of such generator depends on the amount of injected fuel and the load applied to the engine crankshaft. The diesel engine is a nonlinear system. It presents delays, which makes it difficult to control. Diesel engines are equipped with cruise control: mechanical, electromechanical or electronic. It carries out the automatic control of the speed of the diesel engine by adjusting the fuel injection depending on the load. It acts on the acceleration mechanism [16, 23].

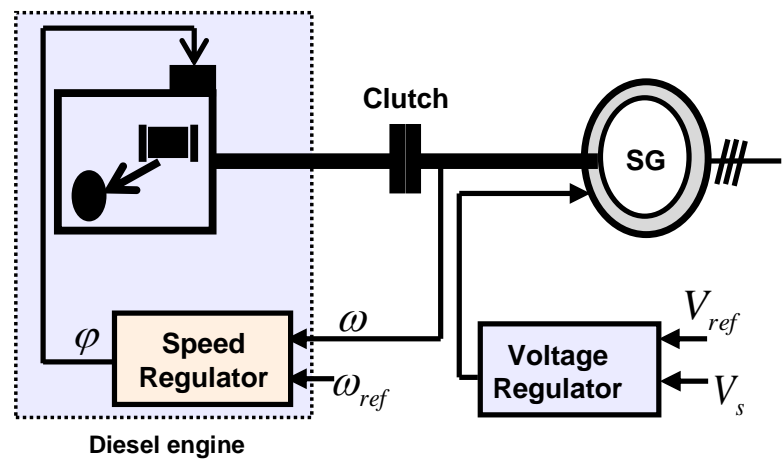

Fig.3. The diesel generator

\section{MODELING OF WIND DIESEL GENERATOR}

To optimize a hybrid power generation system, it is necessary to know the various elements of it. For this, we will begin modeling the wind turbine with the asynchronous generator and as in a second step we model the diesel generator.

\section{A. Modeling the wind system generator}

In the literature, several studies have been devoted to the modeling of different components of a wind power system for a quality generated. A single autonomous wind-poweredturbine model was presented in ${ }^{17}$. The authors in ${ }^{18}$ did an analysis of different modeling methods; the first deals with themodel theoretically; whereasthe second relied on the experimental data.

We can say that wind system transforms wing energy of the air mass to a mechanical power, characterized by the speed of rotation and mechanical torque. (Figure 4). 


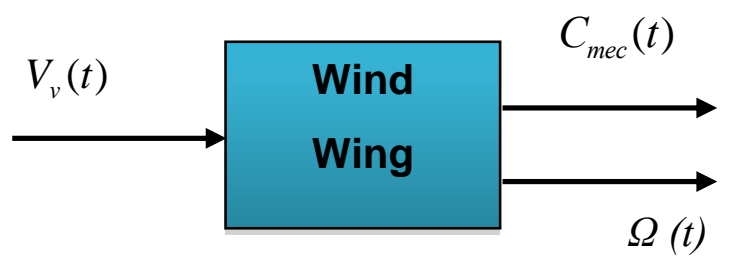

Fig.4. Model of the wing

In our case the turbine is formed with a horizontal axis, the principle of wind conversion was established by Betz.It assumes that the blades are placed in lively air to infinity upstream speedV $_{1}$ and downstream of an infinite speed $V_{2}$ with an air mass moving through the density $\rho$ with surface $S$ of the blades [19].

$m=\frac{\rho \cdot S \cdot\left(V_{1}+V_{2}\right)}{2}$

The powerp $\mathrm{p}_{\mathrm{m}}$; extracted is expressed as half the product of the mass and the change in wind speed.

$P_{m}=\frac{m \cdot\left(V_{1}^{2}-V_{2}^{2}\right)}{2}$

By replacing the expression of $m$ in the equation Number (2)

$P_{m}=\frac{\rho \cdot m \cdot\left(V_{1}+V_{2}\right)\left(V_{1}^{2}-V_{2}^{2}\right)}{2}$

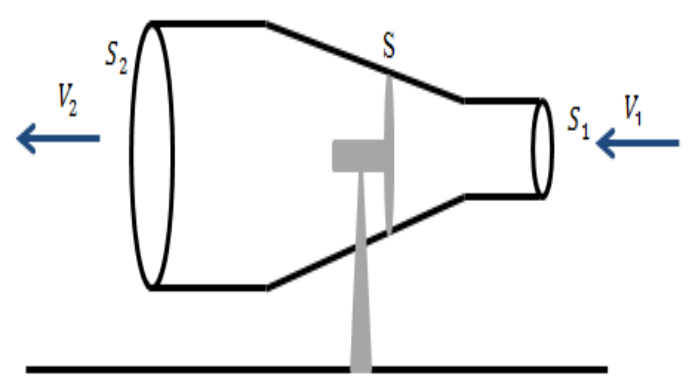

Fig.5. Tube of the current around the wind system

Undisturbed wind theoretically pass through the same area $\mathrm{S}$ with no variation in speed $V_{1}$, the total power $p_{m t}$ would be written:

$P_{m t}=\frac{\rho \cdot S \cdot V_{1}^{3}}{2}$

The ratio of the power extracted from the wind and the total power available is:

$C_{p}=\frac{P_{m}}{P_{m t}}=\frac{\left(1+\left(\frac{V_{1}}{V_{2}}\right)\right) \cdot\left(1-\left(\frac{V_{1}}{V_{2}}\right)^{2}\right)}{2}$

Where $C_{p}:$ The power coefficient

If we represent the corresponding feature in the equation above, we see that the power coefficient
$C_{p}$ has a maximum of 0.59 , see Figure 6 . This theoretical limit called Betz limit which determines the maximum extractable power for a given wind speed. The evolution of the power coefficient is a specific data for each wind [20].

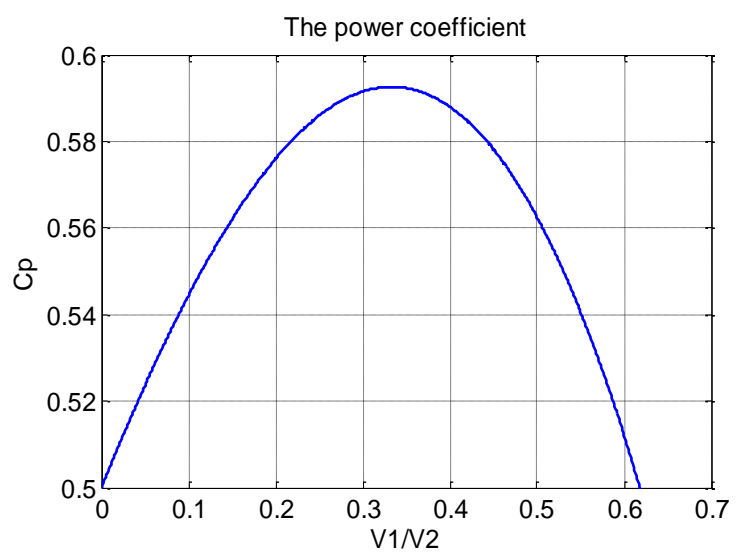

Fig.6. Coefficient of power

With the combination of the equations (1), (4) and (5),the mechanical power $\mathrm{P}_{\mathrm{m}}$ available on the shaft of a wind turbine is expressed by [19]:

$P_{m}=\frac{P_{m}}{P_{m t}} \cdot P_{m t}=C_{p} \cdot P_{m t}=\frac{1}{2} C_{p}(\lambda) \cdot p \cdot \pi \cdot R^{2} \cdot V_{2}^{3}$

The specific rate $\lambda$ is written as follows:

$\lambda=\frac{\Omega_{1} \cdot R}{V_{1}}$

Given the ratio of speed multiplier K, the mechanical power $p_{m g}$ available on the shaft of the electric generator is expressed by:

$P_{m g}=\frac{1}{2} \cdot C_{p}\left(\frac{\Omega_{2} R}{K V_{1}}\right) \cdot \rho \cdot \pi \cdot R^{2} \cdot V_{1}^{3}$

With:

$R$ : Radius of the wind turbine

$\Omega_{1}$ : Rotational speed before the multiplier

$\Omega_{2}$ :Rotational speed after the multiplier

\section{B. Modeling the wind system generator}

Modeling of the diesel engine must consider the moving parts of the engine, the power output $p_{i}$ and the total power dissipated $\mathrm{P}_{\text {diss }} p_{\text {diss }} \mathrm{P}_{\text {diss. }}$. The motor runs at constant speed for a given order to maintain the voltage and frequency of the current supplied by the alternator constant load. The principle of energy conversion can be written as follows [21]:

$$
P_{i}-P_{\text {diss }}=0
$$


The power delivered can be represented by the following expression:

$P_{i}=P_{c i} \cdot n_{i} \cdot m_{f}$

With

$P_{c i}:$ The calorific value of the fuel

$n_{i}:$ The indicated engine performance

$m_{f}$ :The flow of fuel injected into the combustion chamber

The total dissipated power includes the effect of friction of the moving parts as (rods, pistons, crankshaft), and that of the load applied on the engine, can be expressed by the following formula:

$P_{d i s s}=P_{m f} \cdot \frac{C_{y}}{4 \pi} \cdot \omega+C_{r} \cdot \omega$

$P_{m f}:$ The average pressure of the friction losses

$C_{y}$ :The total displacement of the engine

$C_{r}$ : The resistive torque to the applied load

The modeling of friction at different parts of the engine was the subject of numerous studies that lead to a variety of forms. Given the complexity to treat each element separately, it was preferred to use the comprehensive assessment of the losses formulas [22].

The most accurate formula which represents the variation of the power of friction depending on the speed and pressure of the intake air of the engine as follows:

$P_{m f}=\left(1+\omega \cdot S_{e n g} \cdot\left(K_{f 1}+K_{f 2} \cdot \frac{P_{i n}}{P_{a}}\right)+K_{f 3} \omega^{2}\right) \cdot P_{a} \cdot \frac{C_{y}}{4 \pi} \cdot \omega$

\section{SIMULATION OF WIND DIESEL SYSTEM}

The general structure of the wind diesel system is illustrated by Figure 7.

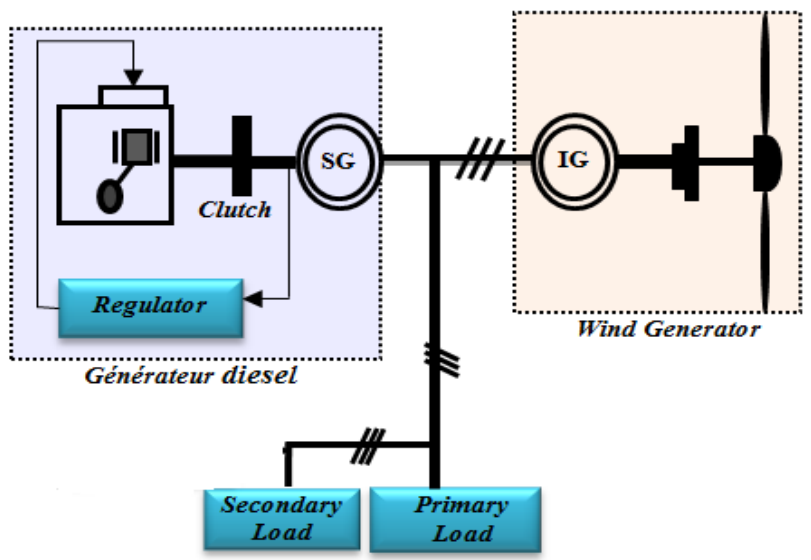

Fig.7. Tube of the current around the wind system
In our system the configuration of the electrical energy provided by means of a system consisting of a wind turbine connected to an asynchronous generator with an apparent power 250kVA diesel and another system which comprises a diesel engine coupled to a permanent magnet synchronous generator with power of $300 \mathrm{kVA}$, which provides the necessary reagent to initiate the asynchronous generator. This hybrid power generation system feeds a load of $250 \mathrm{~kW}$ and a secondary variable load associated with a frequency regulator. The system operates on a voltage of $380 \mathrm{~V}$ and a frequency of $50 \mathrm{~Hz}$. The simulation time is $20 \mathrm{~s}$ with a sampling period of $1 \mathrm{~ms}$. The primary load is $120 \mathrm{~kW}$ up to $\mathrm{t}=5 \mathrm{~s}$, at this time we add another charge to reach a total 250kW (Figure 8). The simulation results are shown in the figures below.

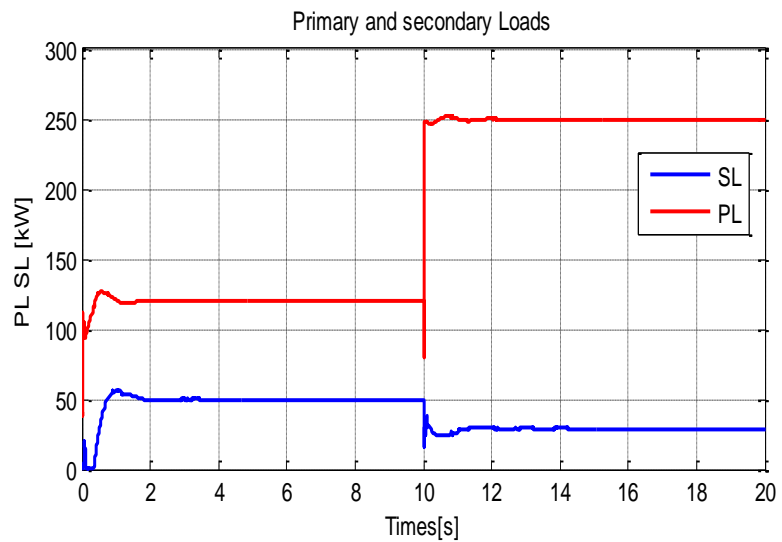

Fig.8. Primary and secondary load

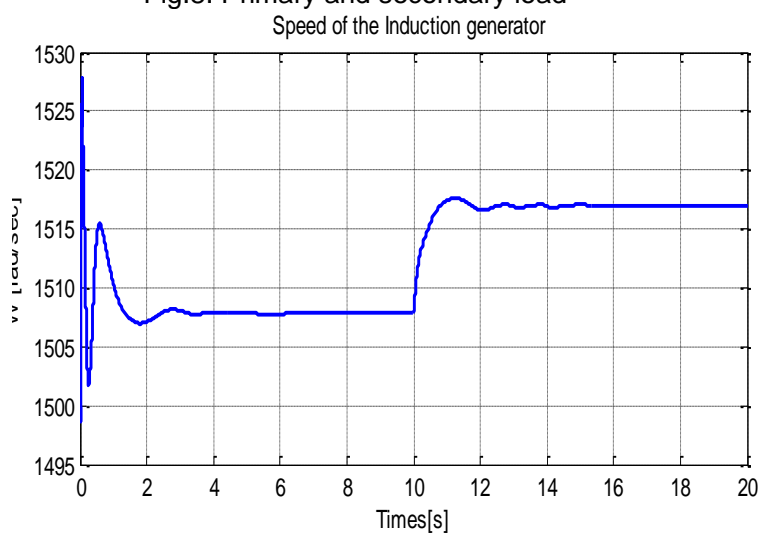

Fig.9. Speed of the asynchronous generator

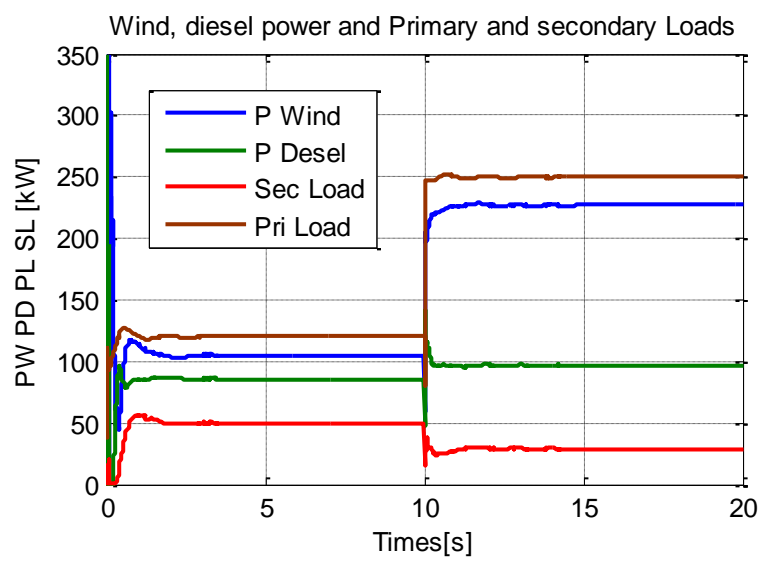

Fig.10. Power in the hybrid system 


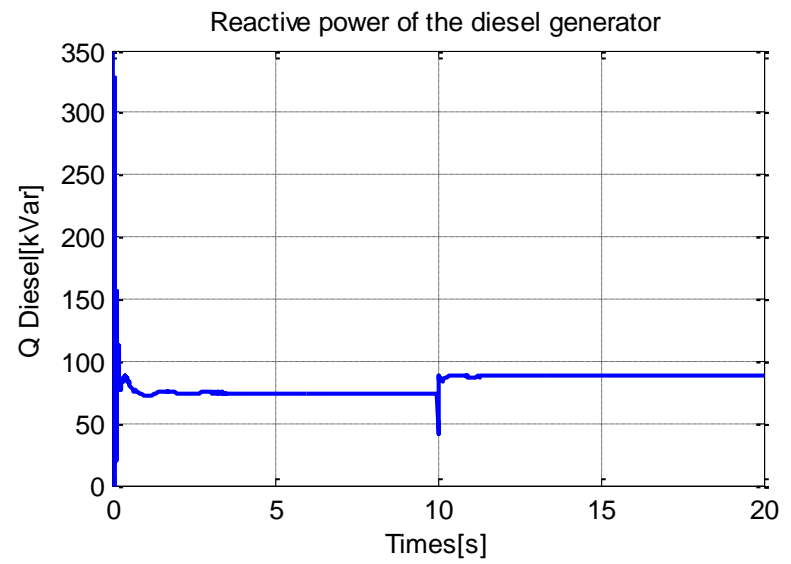

Fig.11. Reactive power of the diesel generator Load Voltage

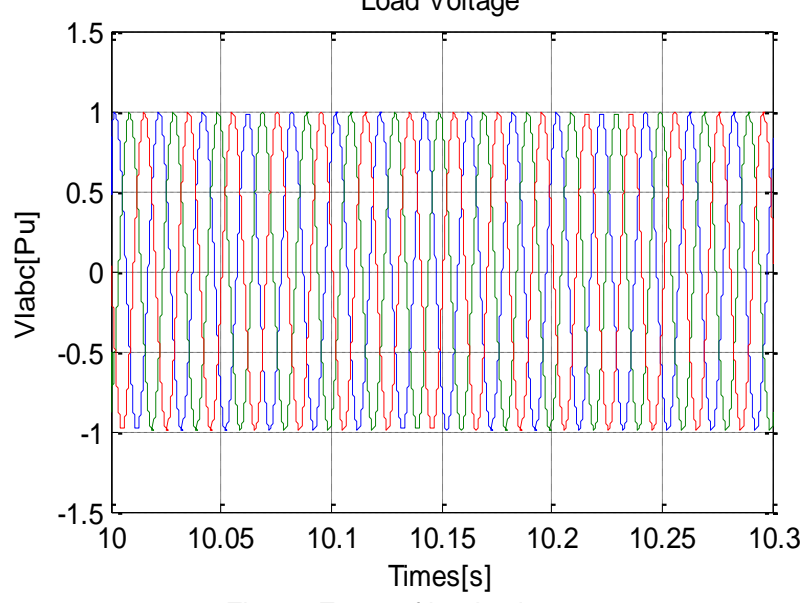

Fig.12. Zoom of load voltage

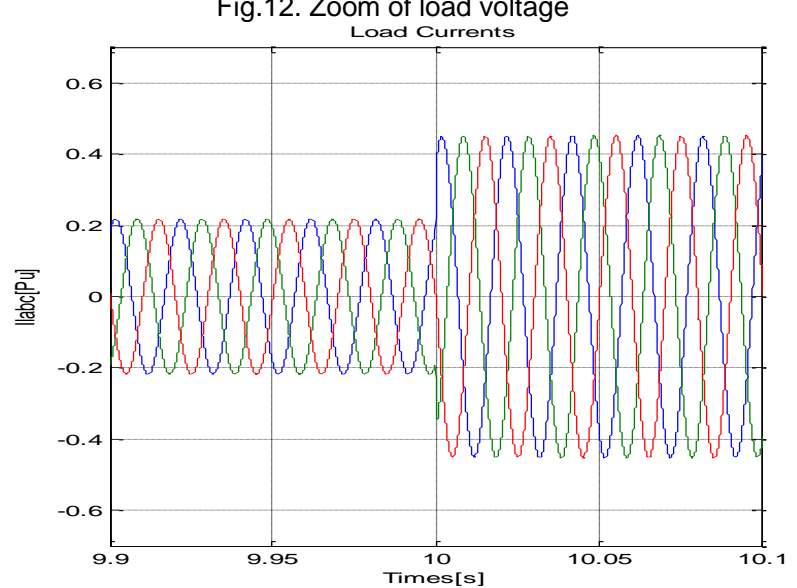

Fig.13.Zoom of the Load Currents

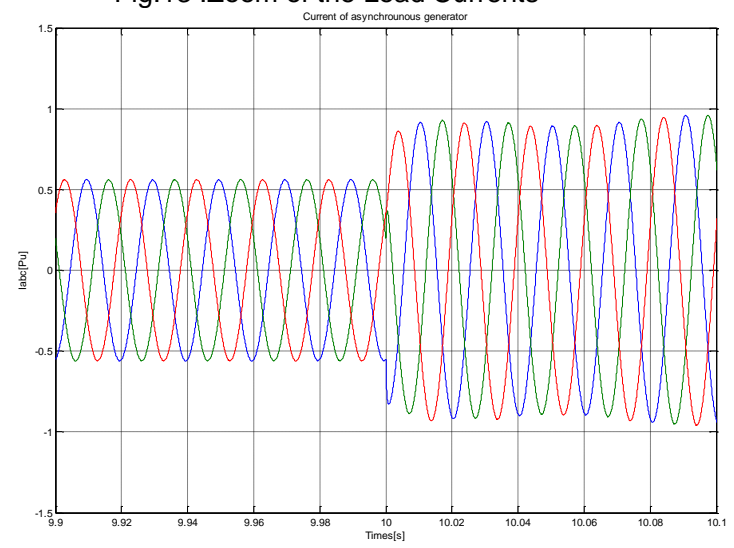

Fig.14. Zoom of the wind currents

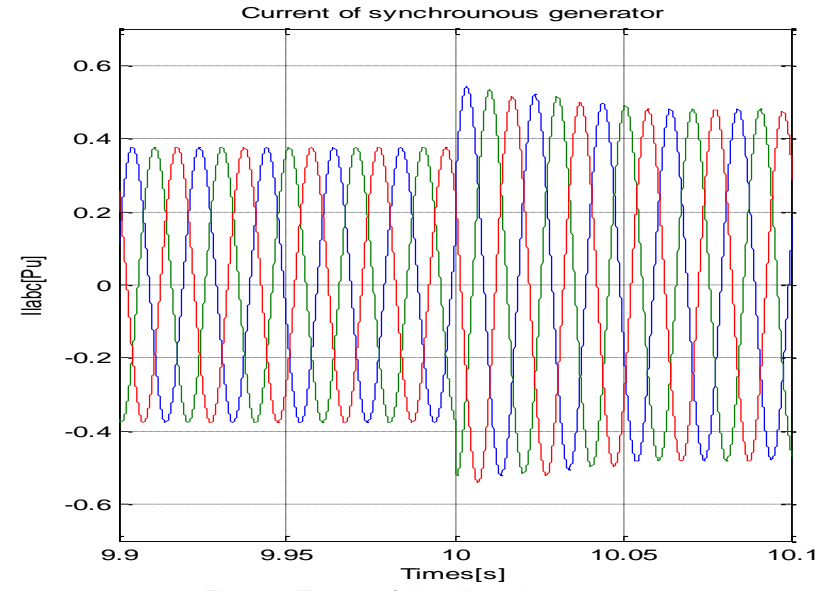

Fig.15. Zoom of the diesel currents

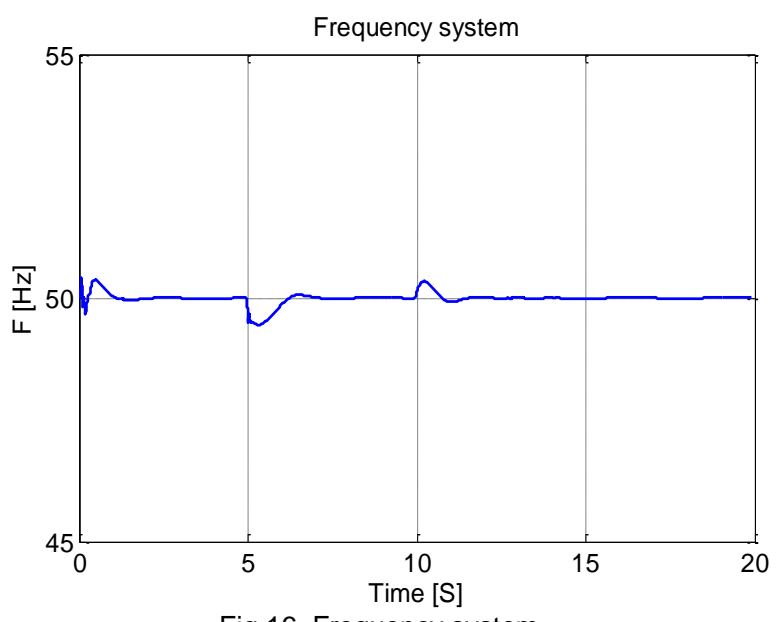

Fig.16 .Frequency system

From the simulation results it is noted that the turbine connected to the induction generator operates at a speed which is slightly greater than the synchronous speed (figure 9).

We note that at $t=5 s$ the total load power is $250 \mathrm{~kW}$ and according to the characteristic of the turbine for a wind speed $8 \mathrm{~m} / \mathrm{s}$, the power generated by the wind turbine is $120 \mathrm{~kW}$, the latter is less the total power of the load, and for that at this moment the power generated by the diesel generator increases (figure 10) to meet the demand.

In the same figure at time $t=10 \mathrm{~s}$, we note that if the wind speed increases $(8$ to $10 \mathrm{~m} / \mathrm{s}$ ), the power supplied by the wind system increases, the power supplied by diesel generator decreases, which leads to a decrease the fuel consumption which is accompanied by a proportional reduction in toxic emissions and greenhouse gas emissions. Conversely, if the wind speed decreases again, the power of GAS decreases power diesel generator (that of the GS) increases to ensure the power demanded by the load. Figure 11 shows the required reactive power generated by the diesel system to initiate the asynchronous generator. The load voltage and load, wind diesel currents are in sinusoidal shapes, see Figuress (12-15). The phase current has fewer ripples and a nearly sinusoidal 
wave form. Figure 14 shows that the frequency regulator maintains the frequency of the load at $50 \mathrm{~Hz}$, after some changes are made in the load.

\section{CONCLUSION}

In This paper we have discussed a modeling of a micro-grid with Wind-Diesel generator hybrid system and its operations. The simulations in MatlabSimulink are presented. According to these simulation results we show the importance and flexibility of operation of a diesel generator and a wind generator to reduce fuel consumption which is associated with a proportional reduction in toxic emissions and greenhouse gas emissions. We also showed how to improve the power quality of wind generation system by means of a wind-diesel hybrid system.

\section{REFERENCES}

[1] Supriyadi A.N and Hashiguchi T., Control Scheme of Hybrid Wind-Diesel Power Generation System, Japon Indonisia.

[2] Sebastiin, R. ,Castro, M. ,Sancristobal, E., Yeves, F. and Peire J., Approaching Hybrid Wind-Diesel Systems and Controller Area Network. Ciudad University. Spain.

[3] Borowy, B.S. Ziyad Salameh M., (September 1994) Optimum Photovoltaic Array Size for a Hybrid Wind/PV System, IEEE Transactions on Energy Conversion, Vol. 9, No. 3,

[4] Trifkovic,M. ,Sheikhzadeh,M., Nigim K. and Daoutidis,P. Hybrid Energy System Modeling and Control, University of Minnesota, Canada.

[5] Devine, M.M. (February 2005) Analysis of Electric Loads and Wind- Diesel Energy Options for Remote Power Stations in Alaska, University of Massachusetts: Amherst. Master.

[6] Rekioua, D., Z. Roumila et Rekioua T. (2008), Etude d'une Centrale Hybride Photovoltaïque - Éolien Diesel, University A. Mira, Bejaia. Bejaia, Algeria

[7] Al-Masood,N. Mirza, R. and Jubaer, A.(2011) Design of a Cost Effective Off-Grid Wind-Diesel Hybrid Power System in an Island of Bangladesh, World Academy of Science, Engineering and Technology 60.

[8] Stott, P.A. and Mueller, M.A. Modelling Fully Variable Speed Hybrid Wind Diesel Systems, Edinburgh University, UK.

[9] Murthy,S.S. Mishra,S. Mallesham, G. and Sekhar,P. C. (December 2010) Voltage and Frequency Control of Wind Diesel Hybrid System with Variable Speed Wind Turbine, IEEE magazine 20-23.

[10] Panickar,P. S. S. ,Rahman,S. Islam, M. and Pryor,T. L. Adaptive Control Strategies in Wind-Diesel Hybrid Systems, Curtin University, Western Australia.

[11] Taylor ,J.H. and Kebede,D. (1995) Modeling and Simulation of Hybrid Systems, University of New Brunswick. Conference on Decision \& Control. Canada.

[12] Kasera,J., Chaplot, A. and Jai, K. (2012) Maherchandani, Modeling and Simulation of Wind-PV Hybrid Power System using MATLAB/Simulink, IEEE Students' Conference on Electrical, Electronics and Computer Science.
[13] Kansara, B.U and . Parekh, B.R (2011) Modelling and Simulation of Distributed Generation System Using HOMER Software, International Conference on Recent Advancements in Electrical.

[14] Ibrahima,H. Ilincaa ,A. and Younesc, R. (2007) Study of a Hybrid Wind-Diesel System with Compressed Air Energy Storage, IEEE Electrical Power Conference. Canada.

[15] Ibrahim,H., Lefebvre, J., Methot, J. F. and Deschenes, J. S. (2011) No-Storage Wind-Diesel System: Mechanical Modeling Based on Power Flow Models, IEEE electrical power conference.

[16] Vechiu, I. (2005) Modelling and Analysis of the Renewable Energy Integration in an Autonomous Grid, PhD thesis. University de Havre..

[17] Idjdarene1, K.( December 2008)Contrôle d'une Génératrice Asynchrone à Cage dédiée à la Conversion de L'énergie Éolienne, JCGE'08 Lyon..

[18] J. Chen and D. Jiang, Study on Modeling and Simulation of Non-grid Connected Wind Turbine, Tsinghua University. China.

[19] Poitiers, F. (2003)Study and Control of Induction Generators for Wind Energy Conversion Systems, PhD thesis. University of Nantes..

[20] Heier,S. (1998) Grid Integration of Wind Energy Conversion Systems. Publications John Wiley \& Sons.

[21] Ibrahim,H. R. ,Younès, A., Ilinca, M. Dimitrova and Perron, J. May (2010) Study and Design of a Hybrid Wind-Diesel System with Compressed Air Energy Storage System for Remote Areas, Applied Energy, Vol. 87, Issue 5, pp 1749-1762,.

[22] Younes,R. (1993) Elaboration d'un modèle de connaissance du moteur diesel avec turbocompresseur à géométrie variable en vue de l'optimisation de ses émissions, PhD Thesis. École Centrale de Lyon. France.

[23] Gagnon, R. Saulnier,B. Sybille, G. and Giroux, P. (April 2002) Modeling of a Generic High-Penetration No-Storage Wind-Diesel System Using Matlab/Power System Blockse.Global Windpower Conference, Paris, France. 